\title{
Bronchiectasis: moving from an orphan disease to an unpleasant socioeconomic burden
}

\author{
Rodrigo Abensur Athanazio (D)
}

Divisão de Pneumologia, Instituto do Coração (InCor), Hospital das Clinicas (HCFMUSP), Faculdade de Medicina, Universidade de São Paulo, São Paulo, Brazil.

Corresponding author: Rodrigo Abensur Athanazio (rathanazio@yahoo.com.br)

\begin{abstract}
Shareable abstract (@ERSpublications)
Bronchiectasis has received increasing attention in recent years. At the same time, studies have shown a high incidence of this disease, especially in older populations, associated with high health-related costs and economic burden. https://bit.ly/2WPfVZ7
\end{abstract}

Cite this article as: Athanazio RA. Bronchiectasis: moving from an orphan disease to an unpleasant socioeconomic burden. ERJ Open Res 2021; 7: 00507-2021 [DOI: 10.1183/23120541.00507-2021].

Copyright @The authors 2021

This version is distributed under the terms of the Creative Commons Attribution NonCommercial Licence 4.0. For commercial reproduction rights and permissions contact permissions@ersnet.org

Received: 16 Aug 2021 Accepted: 17 Aug 2021

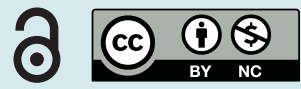

Bronchiectasis is a complex and heterogeneous condition characterised by persistent airway dilation, mucus hypersecretion, and recurrent respiratory infectious exacerbations. Numerous diseases and external insults may trigger the process of developing bronchiectasis, which makes the management of this disease even more challenging [1]. Until a few decades ago, bronchiectasis was considered an orphan disease due to its low prevalence, little recognition of its importance even by pulmonologists, and lack of proven effective therapies for its management. However, in recent years, bronchiectasis has no longer been considered an orphan disease [2]. The improvement and greater availability of diagnostic imaging methods associated with new studies aimed to understand the pathophysiology of bronchiectasis has opened a new chapter for this disease [3]. Several studies started to demonstrate a considerable increase in both the incidence and prevalence of this condition, especially in older populations [4]. Although bronchiectasis characteristics may vary according to the country and socioeconomic status of the targeted population, recent studies show prevalence values between 67 and 566 per 100000 inhabitants [5-7].

As expected, this large number of patients awakened the recognition of an unmet need for effective therapeutic interventions for the management of bronchiectasis. Several clinical trials and guidelines have been published, with the aim of improving quality of life, reducing the number of infectious pulmonary exacerbations, and delaying disease progression [8-10]. The main recommended treatments for the management of patients with bronchiectasis are use of techniques to improve mucociliary clearance (respiratory physiotherapy, hypertonic saline), and long-term use of macrolides, bronchodilators and inhaled antibiotics $[11,12]$. One important feature of patients with bronchiectasis is the higher risk for chronic airway infection by potentially pathogenic microorganisms such as Pseudomonas aeruginosa. These infections are associated with greater lung function decline, increased number of exacerbations and reduced life expectancy [13]. Due to the recurrent use of several courses of oral antibiotics and severity of some patients, many episodes of exacerbations require hospital admission for intravenous antibiotic therapy, with a minimum recommended duration of 10-14 days [8-10]. It is logical to expect that this equation of greater recognition of bronchiectasis cases plus high daily therapeutic load necessity plus high number of exacerbations, including the need for hospitalisation for long periods, would result in a high expenditure of health-related resources.

In this issue of ERJ Open Research, PHuA et al. [14] have comprehensively evaluated the prevalence and incidence of bronchiectasis requiring hospitalisation in Singapore, as well as the associated healthcare utilisation and costs. They found high age-standardised incidence of hospitalised bronchiectasis that declined from 13.9 per 100000 persons in 2007 to 10.6 per 100000 persons in 2017 (an average decline of $2.7 \%$ per year). The incidence rate of bronchiectasis increased sharply with age for both men and women, as previously described [4]. It is important to emphasise that in this present study, only patients 
who had hospitalisations related to bronchiectasis were included. Milder cases that did not require hospitalisation during the evaluated period were not considered. However, the impossibility of including these cases in the study analysis does not diminish the importance of its results. In fact, it reinforces the great economic impact of this condition, since health-related expenses with bronchiectasis should be even higher. The authors found that the annual direct medical cost associated with bronchiectasis was USD 9.6 million in 2017. The majority of this cost was due to hospitalisation, representing $55.8 \%$ of direct medical costs. It is interesting to note that there has been an average annual increase of $5.0 \%$ for inpatient cost per patient (USD 4032 in 2007 versus USD 6563 in 2017), which reflects the increasing complexity of treating these patients [14]. These data are in agreement with other recent publications that have also demonstrated the great economic burden related to bronchiectasis. In the USA, when compared to matched controls, patients with bronchiectasis showed an increase of USD 2319 and USD 1607 in general and respiratory costs [15]. In Germany, the direct expenditure with bronchiectasis was $31.0 \%$ higher than matched controls (mean EUR 18634.57 versus EUR 14236.99) [16].

It is interesting to note that, as found by PHuA et al. [14], in other studies most health expenditures related to bronchiectasis were linked to hospitalisations $[16,17]$. Despite the existence of variability in the rate of hospitalisation related to bronchiectasis between countries, the impact of this condition on health systems is unquestionable. It varied from 9.4 hospitalisations per 100000 inhabitants in Germany [18] to 16.5 hospitalisations per 100000 inhabitants in the USA and Spain [19, 20]. In addition, patients with bronchiectasis have higher hospital costs compared with matched controls [15, 16]. However, several other costs must be taken into account when assessing patients with bronchiectasis. These patients also have high expenses related to their outpatient treatments [16, 17]. The global economic burden of bronchiectasis is far deeper than previously expected. All costs related to this condition should be considered (table 1) and we may find many new challenges while we keep digging.

Another important aspect related to bronchiectasis expenses is that the greater the severity of the disease, the higher its healthcare costs. A Spanish study showed that the mean annual costs per patient were EUR 2993, EUR 4732 and EUR 9999 for mild, moderate and severe bronchiectasis, respectively [17]. This finding reinforces the importance of early recognition of this disease. This way, therapeutic measures can be quickly implemented and, consequently, prevent the progression of bronchiectasis to more severe stages. Furthermore, the recognition of disease-related costs allows interventions to be instituted with the objective not only of reducing the economic burden but also of improving patients' quality of life. A good example is the incorporation of domiciliary programmes with intravenous antibiotic therapy, which has already proven to be a safe and effective intervention both in terms of cost reduction and in improving patient satisfaction when compared to conventional hospitalised care [21].

When facing a disease as heterogeneous as bronchiectasis is, we should expect different results according to countries and regions. This is a relevant topic since not every finding can be promptly extrapolated to the reality of other populations. In this study by PHUA et al. [14], they found a decline in the age-standardised incidence of hospitalised bronchiectasis over time. One of the reasons attributed by the authors for this finding was the significant reduction in tuberculosis cases in Singapore in recent years [14], since Mycobacterium tuberculosis infection is a well-recognised cause of bronchiectasis. Unfortunately, this is still not reality for several South American, African and Asian countries [22]. In addition, sociodemographic

TABLE 1 Economic burden of bronchiectasis

\begin{tabular}{|c|c|c|c|}
\hline Outpatient direct costs & Inpatient direct costs & Advanced disease costs & Indirect costs \\
\hline Medication costs & Length of stay & Long-term oxygen therapy & $\begin{array}{l}\text { Work productivity impairment (absenteeism } \\
\text { and presenteeism) }\end{array}$ \\
\hline Medical appointments & Intravenous antibiotics & Non-invasive ventilation & Disability and early retirement \\
\hline Physiotherapy & ICU resources & Lung transplantation & Limitations of daily life \\
\hline Pulmonary rehabilitation & Inpatient physiotherapy & & Caregiver burden \\
\hline Treatment of exacerbations & Imaging and laboratory exams & & \\
\hline Treatment of complications & Treatment of complications & & \\
\hline \multicolumn{4}{|l|}{ Sputum microbiology } \\
\hline \multicolumn{4}{|l|}{ Radiology } \\
\hline Laboratory exams & & & \\
\hline
\end{tabular}


characteristics may differ across regions. For example, the average age of the bronchiectasis population in South America tends to be lower when compared to the European and North American population [23]. These findings highlight the importance of local data in order to allow this complex scenario of bronchiectasis to be better understood while taking into account all particularities inherent to this pathology.

It is undeniable that our scientific knowledge related to bronchiectasis has significantly evolved. In recent years, we have experienced an exponential increase in studies focused on unravelling the pathophysiology of bronchiectasis, on testing different therapeutic interventions and on evaluating its socioeconomic burden. All players (patients, healthcare professionals and payers) will benefit from this. However, we are still seeing only the tip of the iceberg and we have a long road to walk before identifying the appropriate safe and cost-effective interventions for bronchiectasis management.

Provenance: Commissioned article, peer reviewed.

Conflict of interest: None declared.

References

1 McShane PJ, Naureckas ET, Tino G, et al. Non-cystic fibrosis bronchiectasis. Am J Respir Crit Care Med 2013; 188: 647-656.

2 European Medicines Agency. Human Regulatory. Orphan Designation: Overview. www.ema.europa.eu/en/ human-regulatory/overview/orphan-designation-overview Date last accessed: 16 August 2021.

3 Keir HR, Chalmers JD. Pathophysiology of bronchiectasis. Semin Respir Crit Care Med 2021; 42: 499-512.

4 Lin JL, Xu JF, Qu JM. Bronchiectasis in China. Ann Am Thorac Soc 2016; 13: 609-616.

5 Ringshausen FC, de Roux A, Diel R, et al. Bronchiectasis in Germany: a population-based estimation of disease prevalence. Eur Respir J 2015; 46: 1805-1807.

6 Monteagudo M, Rodríguez-Blanco T, Barrecheguren M, et al. Prevalence and incidence of bronchiectasis in Catalonia, Spain: a population-based study. Respir Med 2016; 121: 26-31.

7 Weycker D, Hansen GL, Seifer FD. Prevalence and incidence of noncystic fibrosis bronchiectasis among US adults in 2013. Chron Respir Dis 2017; 14: 377-384.

8 Polverino E, Goeminne PC, McDonnell MJ, et al. European Respiratory Society guidelines for the management of adult bronchiectasis. Eur Respir J 2017; 50: 1700629.

9 Pereira MC, Athanazio RA, Dalcin PTR, et al. Brazilian consensus on non-cystic fibrosis bronchiectasis. $J$ Bras Pneumol 2019; 45: e20190122.

10 Martínez-García MÁ, Máiz L, Olveira C, et al. Spanish guidelines on treatment of bronchiectasis in adults. Arch Bronconeumol 2018; 54: 88-98.

11 Chalmers JD, Chotirmall SH. Bronchiectasis: new therapies and new perspectives. Lancet Respir Med 2018; 6 : 715-726.

12 Athanazio R, da Costa JC, de la Rosa Carrillo D, et al. Current and future pharmacotherapy options for non-cystic fibrosis bronchiectasis. Expert Rev Respir Med 2018; 12: 569-584.

13 Araújo D, Shteinberg M, Aliberti S, et al. The independent contribution of Pseudomonas aeruginosa infection to long-term clinical outcomes in bronchiectasis. Eur Respir J 2018; 51: 1701953.

14 Phua HP, Lim W-Y, Ganesan G, et al. Epidemiology and economic burden of bronchiectasis requiring hospitalisation in Singapore. ERJ Open Res 2021; 7: 00334-2021.

15 Joish VN, Spilsbury-Cantalupo M, Operschall E, et al. Economic burden of non-cystic fibrosis bronchiectasis in the first year after diagnosis from a US health plan perspective. Appl Health Econ Health Policy 2013; 11: 299-304.

16 Diel R, Chalmers JD, Rabe KF, et al. Economic burden of bronchiectasis in Germany. Eur Respir J 2019; 53: 1802033.

17 de la Rosa Carrillo D, Navarro Rolon A, Girón Moreno RM, et al. Cost of hospitalizations due to exacerbation in patients with non-cystic fibrosis bronchiectasis. Respiration 2018; 96: 406-416.

18 Ringshausen FC, de Roux A, Pletz MW, et al. Bronchiectasis-associated hospitalizations in Germany, 20052011: a population-based study of disease burden and trends. PLoS One 2013; 8: e71109.

19 Sánchez-Muñoz G, López de Andrés A, Jiménez-García R, et al. Time trends in hospital admissions for bronchiectasis: analysis of the Spanish national hospital discharge data (2004 to 2013). PLoS One 2016; 11: e0162282.

20 Seitz AE, Olivier KN, Steiner CA, et al. Trends and burden of bronchiectasis-associated hospitalizations in the United States, 1993-2006. Chest 2010; 138: 944-949.

21 Bedi P, Sidhu MK, Donaldson LS, et al. A prospective cohort study of the use of domiciliary intravenous antibiotics in bronchiectasis. NPJ Prim Care Respir Med 2014; 24: 14090. 
22 Reid MJA, Arinaminpathy N, Bloom A, et al. Building a tuberculosis-free world: the Lancet commission on tuberculosis. Lancet 2019; 393: 1331-1384.

23 Athanazio R, Pereira MC, Gramblicka G, et al. Latin America validation of FACED score in patients with bronchiectasis: an analysis of six cohorts. BMC Pulm Med 2017; 17: 73. 